\title{
Epidemiology of Needle Sticks and Sharp Injuries Among Nurses in an Iranian Teaching Hospital
}

\author{
Seyyedeh Roghayeh Ehsani ${ }^{1}$, Esmaeil Mohammadnejad ${ }^{2,}$, Mohammad Reza Hadizadeh ${ }^{3}$, \\ Javad Mozaffari ${ }^{4}$, Simin Ranjbaran ${ }^{1}$, Roghyeh Deljo ${ }^{1}$, Sedigheh Deljo ${ }^{1}$ \\ 1 Imam Khomeini Clinical Hospital Complex, Tehran University of Medical Sciences, Tehran, IR Iran \\ ${ }_{2}^{2}$ Department of Nursing, International Branch, Shahid Beheshti University of Medical Sciences, Tehran, IR Iran \\ ${ }^{3}$ Department of Infectious Diseases, Mashhad University of Medical Sciences, Mashhad, IR Iran \\ 4 Faculty of Medicine, Ahvaz Jundishapur University of Medical Sciences, Ahvaz, IR Iran \\ ${ }^{*}$ Corresponding author: Esmaeil Mohammadnejad, Department of Nursing, International Branch, Shahid Beheshti University of Medical Sciences, Tehran, IR Iran. Tel.: +98- \\ 2166936626, Fax:+98-2166936626, E-mail: asreno1358@yahoo.com.
}

Received: September 16, 2012; Revised: October 17, 2012; Accepted: November 20, 2012

\begin{abstract}
Introduction: Needle stick injuries (NSI) are major occupational hazards for health care workers.
Objectives: This study aimed to determine the Epidemiology of needle sticks and sharp injuries among nurses of an Iranian Teaching Hospital.

Materials and Methods: This descriptive cross-sectional study was conducted in 2009 on 328 nurses in a health center in Tehran. Stratified random samples were selected among the staff. Data were collected through a questionnaire prepared for this study and were analyzed with the SPSS software version 15 , by using descriptive and analytical statistical methods.

Results: The results showed that $45.12 \%$ of the employees' occupational injuries were caused by sharp objects. Regarding the type of device, needle and angiocath needle had caused the most serious injuries with a frequency of $43.91 \%$ and $29.05 \%$, respectively. After the injury incidence, $41.87 \%$ of the health staff only washed the injury area with adequate soap and water and $76.82 \%$ of the nurses have received the hepatitis B vaccination. The injury mostly occurred in the emergency department due to the overcrowding in the ward and the staff fatigue. There were significant associations between the staff age as well as the ward with the extent of injuries.

Conclusions: Needle stick injuries are common among nurses and are often not reported. Improved standard infection control precautions (SICPs) policy and reporting strategies are needed in order to increase occupational safety for nurses.
\end{abstract}

Keywords: Needlestick Injuries; Health Personnel; Needles

\section{Introduction}

Among the most dangerous circumstances which threaten the health professionals are the injuries resulting from contaminated cutting equipment during operations. Although numerous pathogens can be transmitted by contaminated cutting equipment, transmission of hepatitis B, C and AIDS/HIV are the most prevalent ones (1-3). More than 20 pathogens are transmitted from injuries caused by needles and sharp instruments (4). According to the center for disease control and prevention (CDC) and the conducted studies, the risk of HIVinfected injuries caused by devices is $0.3 \%$, hepatitis $\mathrm{C}$ is between $2.7 \%$ - $10 \%$ and the risk for hepatitis B is $5 \%-45 \%$ among health professionals $(5,6)$. Each year, 600,000 to 800,000 and each day 200 contacts occur with the tip of sharp and cutting objects (7). According to the reports, a blood-borne serious infection can cost a million US dollars concerning performing tests, follow-up, cost of disability and loss of work time. In addition, the cost of preventing the suspected or diagnosed injuries is estimated at 3000 USD (8). Furthermore, the economic cost of injuries caused by sharp objects in the US is estimated to be approximately 51 to 3766 USD. About 14 to 839 cases per 1,000 individuals are working in clinical areas incorporating health care (9). Nine Studies have shown that at least $64 \%$ of health workers have had contact with blood or body fluids at least once during their professional life (10). Ten nurses are the most common groups in medical staff who face needle penetration (11-13).

Implication for health policy/practice/research/medical education:

The authorities and policy makers should implement proper in-service education programs and protocols to help healthcare staff in order to take appropriate actions after needle stick or injuries as such with sharp objects used by hospital managers, nurses and infection control supervisors to reduce nurses' behavior with regard to needle recapping.

Copyright (C) 2013, Infectious Diseases and Tropical Medicine Research Center. This is an open-access article distributed under the terms of the Creative Commons Attribution License, which permits unrestricted use, distribution, and reproduction in any medium, provided the original work is properly cited. 
Estimating the true number of the needle penetration is difficult. About $70 \%$ of these cases are not reported even in countries which have such systematic reporting systems (14). About 35\% of affected cases are not reported in the countries with recordkeeping and reporting protocols (15). Several studies are performed to identify factors leading to damages caused by needle stick, sharp and cutting objects in the world. In these studies, many factors such as individual agents, device, treatment and management with various dimensions have been investigated. It was stated that the most important factors in causing the injuries were long working hours and not having enough sleep during the night shift (16-19).

\section{Objectives}

The present study was conducted in 2009 to determine the prevalence and causes of sharp and cutting object injuries and performance of the nurses in an educational treatment center in Tehran, Iran.

\section{Materials and Methods}

This cross sectional study aimed to determine the prevalence and causes of sharps and cutting objects injuries and performance of the nurses in the one of the educational treatment centers in Tehran in the year of 2009. Data collection tool consisted of two parts: a questionnaire with 10 questions including demographic characteristics and 22 questions relevant to the incidence and the caused damages. The method of content validity was used to determine the validity of the questionnaire and the re-test method for its scientific reliability. The questionnaire was completed through interview with selected individuals who were allowed to choose more than one choice where question was in relevance with actions taken after the injury. In this study the stratified sampling method was used so that in each sector which was relevant to the number of nurses, new nurses would be added to the study. The inclusion criteria for the staff were to first perform at least six consecutive months of nursing services. Second, they did not participate in the similar research before. The questionnaire was anonymous due to the observance of ethics and integrity and the collected information maintained confidential by the researcher at all stages of the study. Participating in this study was due to the informed verbal agreement of all the staff. The coded data were entered in SPSS software version 16. Data analyses were performed using descriptive statistics (frequency, mean and standard deviation for each variable) and analytical statistics (Chi-square, ttests, independent and logistic regression).

\section{Results}

The results showed that the incidence of needle injuries were $45.12 \%$ during their working period and $55.4 \%$ of the mentioned group were injured more than twice. The majority of subjects $(70.42 \%)$ were female and $(60.36 \%)$ married. The mean age was $30.71+3.07$ years who had 9.03 +7.13 years of experience. In terms of education, most of the nurses (90.24\%) had bachelor degree. Regarding the type of device, needle and angicat, at $43.91 \%$ and $29.05 \%$, respectively caused the most injuries and the staff were mostly affected during reloading the needle stick (recapping) (Table1).

Table 1. Distribution of Type and Cause of Damage Resulted by Sharp and Cutting Devices among Nurses in an Educational Hospital in Tehran, Iran

\begin{tabular}{ll}
\hline Distribution & No.(\%) \\
\hline Device & \\
\hline Needle & $65(43.91)$ \\
\hline Scalp & $17(11.48)$ \\
\hline Angiocath needle & $43(29.05)$ \\
\hline Scalpel & $12(8.10)$ \\
\hline Suture needle & $5(3.37)$ \\
\hline Other & $6(4.05)$ \\
\hline Cause & \\
\hline Catheters placement & $28(18.91)$ \\
\hline Needle recapping & $73(49.32)$ \\
\hline Washing contaminated tools & $9(6.08)$ \\
\hline $\begin{array}{l}\text { Injections (intravenous, intramuscular and } \\
\text { subcutaneous) }\end{array}$ & $24(16.21)$ \\
\hline Other & $14(9.45)$ \\
\hline
\end{tabular}

In terms of location of the event, the most injuries were occurred in the emergency department (48.64\%) and in terms of working shifts, the injuries were $15.54 \%$ during the morning shift, $29.72 \%$ during the evening shift and $54.72 \%$ during night shift. This study revealed that $76.82 \%$ of nursing staff who completed the vaccination against hepatitis B and the antibody was also included $90.24 \%$ of the cases. The necessary actions were immediately taken after the damage (e.g. wash with soap and water and disinfection of the damaged area) in $41.87 \%$ of the nurses who injured by needles (Table 1). Moreover, $75.30 \%$ of the nurses were trained in terms of the overall standards (Universal Precaution) and 53.39\% of the injured nursing personnel were not reported to the authorities of the hospital. The most important reasons were unfamiliar due to reporting process and dissatisfaction with follow-up which was carried out by other colleagues. The relationship between age, gender, duration and type of section were evaluated for damages caused by sharp instruments among nurses. A significant relationship was documented between age and type of the section and the mentioned damages $(P<0.05)$. Logistic regression analysis with backward method showed that there was a signif- 
icant relationship between work experience and injury history in the final model $(\mathrm{OR}=1.15, \mathrm{CI}=0.97-1.97)$ which can mean the less experienced the staff is, the greater the history of the injury can be.

\section{Discussion}

The damage caused by the needle sticks and contaminated sharp and cutting objects are amongst high risk injuries. Given current study, the prevalence of these injuries was $45.12 \%$. The prevalence rate was $49.6 \%$ in Askarian study which was conducted on hospital nurses in Fars province, Iran (20).Studies in other countries confirm the risk of injuries by needle sticks. These ratios were different in several studies and represented the need for more attention to this subject by the officials $(21,22)$. The main reason for the high frequency of injury with sharp and cutting objects was needle recapping after its use. Needle recapping was considered to be the most common cause of injury after reviewing numerous studies (15-23). However, using the needle cutter device or boxes for disposal of contaminated needles (safety box) in the clinical sections has been escalating in recent years. It has also been recommended to avoid re-capping the contaminated needles in order to reduce the injury (4).

Given the location of the injury in our study, most of the injuries were occurred in the emergency department, while the study in the State of Qatar showed the highest incidence of injury in the interior section (22). The medical and health professionals, especially the emergency department staff are the most common groups who are at risk of pathogens (11). Damages are more likely to occur in the emergency department because of heavy rush and acceleration in the program of the staff, faster performance of the tasks and dealing with the emergent cases more than the other sections. The rate of injury report among nursing personnel was $46.6 \%$ and the most important reason for not reporting the issue was that the staff appeared to be unfamiliar with the reporting process. A similar study in Iran showed that $23.6 \%$ of nurses reported the injuries the majority of which (97.1\%) was oral (24). Not having enough time, complicated administrative procedures, rate of reported injuries recorded less in the same studies $(14,25)$. The study of Nash et al. indicated that the source of injury affected the nurses' judgments on reporting damages (26). Knight et al. stated that one of the main reasons for not reporting the occurred injury is a myth that the damage is safe and trivial (27). Setting up a registration and reporting system as well as a standard protocol for the country are recommended to not only reduce or eliminate this problem but also to develop a timely reporting for having proper planning.

$82.76 \%$ of the nurses had been fully vaccinated in terms of vaccination coverage against hepatitis. These rates are reported as 66\% in India, $82.7 \%$ in Pakistan and $82 \%$ in Saudi Arabia $(7,15)$. It should be noted that contacting with blood, sharp instruments contaminated with blood and the infectious substances of infected patients are real threats to the health care staff and with on time vaccination can prevent the affection to dangerous diseases. However unfortunately in this case, there are a number of employees who do not take it serious. Therefore, vaccination against hepatitis $B$ is recommended for medical staff and it should be particularly mandatory for nurses. Due to the high rates of injury caused by sharp and cutting objects and in order to reduce and eliminate its affects, the following actions are recommended: prevention of injuries, dealing with the objects under observation of hospital infection control committee, set up a registration system, regular reporting of occupational accidents in hospitals, planning and having a needle stick protocol, accurate measurements of serum viral markers and formation of separate personnel health records for each employer.

\section{Acknowledgements}

The authors forward their sincere thanks to all nursing staff who participated in this study.

\section{Authors' Contribution}

All authors collaborated equally.

\section{Financial Disclosure}

The authors have no conflicts of interest to declare.

\section{Funding/Support}

The authors have no received any financial support related to the material of the manuscript.

\section{References}

1. McGee PA, Cupell LG, Higgins MM, Renshaw MD, Shaver ER. Updated US Public Health Service Guide lines for the management of occupational Exposures to HBV/HCV/HIV and recommendations for post exposure prophylaxis. MMWR; 2001 [updated July 2, 2011]; Available from: http://www.cdc.gov/mmwr/preview/ mmwrhtml/rr5011a1.htm.

2. Leigh JP, Gillen M, Franks P, Sutherland S, Nguyen HH, Steenland $\mathrm{K}$, et al. Costs of needlestick injuries and subsequent hepatitis and HIV infection. Curr Med Res Opin. 2007;23(9):2093-105.

3. Meyer U, Chuard C, Regamey C. [Occupational exposures with risk of transmission of HIV, HBC and HCV in health care workers]. Rev Med Suisse. 2005;1(36):2327-31.

4. Ertem M, Dalar Y, Cevik U, Sahin H. Injury or body fluid splash incidence rate during three months period in elective surgery procedures, at Dicle University Hospital, Diyarbakir, Turkey. Ulus Travma Acil Cerrahi Derg. 2008;14(1):40-5.

5. Zanni GR, Wick JY. Preventing needlestick injuries. Consult Pharm. 2007;22(5): 400-2, 404-6, 409.

6. Schmid K, Schwager C, Drexler H. Needlestick injuries and other occupational exposures to body fluids amongst employees and medical students of a German university: incidence and followup. J Hosp Infect. 2007;65(2):124-30.

7. Mirza S, Siddoque K, Tauqir SF, Anwar I, Malik AZ. Knowledge attitude and practices regarding Needle Stick injuries amongst 
health care providers. PakJ Sur. 2008;24(4):243-8.

8. Dement JM, Epling C, Ostbye T, Pompeii LA, Hunt DL. Blood and body fluid exposure risks among health care workers: results from the Duke Health and Safety Surveillance System. Am J Ind Med. 2004;46(6):637-48.

9. Lee JM, Botteman MF, Xanthakos N, Nicklasson L. Needlestick injuries in the United States. Epidemiologic, economic, and quality of life issues. AAOHN J. 2005;53(3):117-33.

10. Azap A, Ergonul O, Memikoglu KO, Yesilkaya A, Altunsoy A, Boz kurt GY, et al. Occupational exposure to blood and body fluids among health care workers in Ankara, Turkey. Am J Infect Control. 2005;33(1):48-52.

11. Mohammad Nejad E, Jafari S, Mahmoodi M, Begjani J, Ehsani S, Rabirad N. Hepatitis B Virus Antibody Levels in High-Risk Health Care Workers. Hepat Mon. 2011;11(8):662-663.

12. Denis MA, Ecochard R, Bernadet A, Forissier MF, Porst JM, Robert $\mathrm{O}$, et al. Risk of occupational blood exposure in a cohort of 24,000 hospital healthcare workers: position and environment analysis over three years. J Occup Environ Med. 2003;45(3):283-8.

13. Cheraghi MA, Nejad EM, Begjani J, Rabirad N, Ehsani SR, Kaji MA. Knowledgeand attitudes of nurses regarding HIV/AIDS (Tehran-2010). Iran J Clin Infect Dis. 2011;6(3):121-3.

14. Au E, Gossage JA, Bailey SR. The reporting of needlestick injuries sustained in theatre by surgeons: are we under-reporting? J Hosp Infect. 2008;70(1):66-70.

15. Jayanth ST, Kirupakaran H, Brahmadathan KN, Gnanaraj L, Kang G. Needle stick injuries in a tertiary care hospital. Indian J Med Microbiol. 2009;27(1):44-7.

16. Mohammad Nejad E, Sfandbud M, Ehsani SR, Deljo R. [Occupational exposure to Needlestick among nurses]. Irn J Infect Diseas Trop Med . 2009;45(14):47-51.

17. Ayas NT, Barger LK, Cade BE, Hashimoto DM, Rosner B, Cronin JW, et al. Extended work duration and the risk of self-reported percutaneous injuries in interns. JAMA. 2006;296(9):1055-62.

18. Fisman DN, Harris AD, Rubin M, Sorock GS, Mittleman MA. Fatigue increases the risk of injury from sharp devices in medical trainees: results from a case-crossover study. Infect Control Hosp Epidemiol. 2007;28(1):10-7.

19. Mohammadnejad E, Esfanbod M. [Needle sticks injuries reporting among nurses]. Irn J Infect Disease Trop Med.2010;48(15):49-54

20. Askarian M, Shaghaghian S, McLaws ML. Needlestick injuries among nurses of Fars province, Iran. Ann Epidemiol. 2007;17(12):988-92.

21. Smith DR, Mihashi M, Adachi Y, Nakashima Y, Ishitake T. Epidemiology of needlestick and sharps injuries among nurses in a Japanese teaching hospital. J Hosp Infect. 2006;64(1):44-9.

22. Shah SF, Bener A, Al-Kaabi S. The epidemiology of needlestick injuries among health care workers in a newly developed country. SafSci. 2006;44.5:387-94.

23. Guo YL, Shiao J, Chuang YC, Huang KY. Needlestick and sharps injuries among health-care workers in Taiwan. Epidemiol Infect. 1999;122(2):259-65.

24. Nazmieh H, Nauaf-Yarand A, Uanmohammad S, Hosseini F [Assesment of the injuries caused by sharp instruments in the health worker of university hospital in Yazd]. Iran J Nurs. 2005;43(19):49-55.

25. Makary MA, Al-Attar A, Holzmueller CG, Sexton JB, Syin D, Gilson $\mathrm{MM}$, et al. Needlestick injuries among surgeons in training. $N$ Engl J Med. 2007;356(26):2693-9.

26. Nash GF, Goon P. Current attitudes to surgical Needlestick injuries. Ann R Surg Engl. 2000;82(7 Suppl):236-9.

27. Knight VM, Bodsworth NJ. Perceptions and practice of universal blood and body fluid precautions by registered nurses at a major Sydney teaching hospital. J Adv Nurs. 1998;27(4):746-51. 